\title{
Dynamic Modeling and Driving Cycle Prediction for a Racing Series Hybrid Car
}

\author{
Zainab Asus, Student Member, IEEE, El-Hassane Aglzim, Daniela Chrenko, Member, IEEE, \\ Zul-Hilmi Che Daud, Student Member, IEEE, and Luis Le Moyne
}

\begin{abstract}
This paper presents Noao, a plug-in series hybrid racing car equipped with an engine/generator set as range extender. To determine the velocity profile, i.e., performance of the car and its power profile, a dynamic model for this car is developed using pedal position as input. This value is easy to measure, representative for race cycles, and presents a novelty. The model is validated with the results from experiments. An analysis based on the map of Magny-Cours racing circuit and drivers pedal action on certain zones of the circuit is formulated and is used as a prediction tool to determine drivers inputs on other racing circuits and generate driving schedules. The results obtained from this analysis are essential to predict energy consumption of the system, estimate driving range, and inspect battery state-of-charge evolution of the car during races. Moreover, the generated driving cycle provides an optimum compromise between drivetime and energy consumption of the system.
\end{abstract}

Index Terms-Driving cycle, dynamic model, engine/battery, racing car, series hybrid.

\begin{tabular}{ll} 
& \multicolumn{1}{c}{ NomENCLATURE } \\
$A$ & Area $\left(\mathrm{m}^{2}\right)$. \\
$B$ & Battery. \\
$C_{x}$ & Drag coefficient $(-)$. \\
$C_{t}$ & Battery capacity $(\mathrm{kWh})$. \\
$\mathrm{DP}$ & Dynamic programming. \\
$\mathrm{E} / \mathrm{G}$ & Engine generator. \\
EM & Electric motor. \\
EMR & Energetic macroscopic representation. \\
ESS & Energy storage system. \\
FT & Fuel tank. \\
$F$ & Force (N). \\
$G$ & Generator. \\
GIS & Geographical information systems. \\
GPS & Global positioning systems. \\
HEV & Hybrid electric vehicle. \\
$I$ & Current (A). \\
$I_{\mathrm{em}}, I_{p}, I_{w} \quad$ Polar moment of inertia (kgm $\left.{ }^{2}\right)$. \\
\end{tabular}

\begin{tabular}{|c|c|}
\hline ICE & Internal combustion engine. \\
\hline LHV & Lower heating value $\left(\mathrm{MJ} \mathrm{kg}^{-1}\right)$. \\
\hline$L_{N}$ & Length of problem. \\
\hline MPC & Model predictive control. \\
\hline$N$ & Number of timesteps. \\
\hline$P$ & Pressure $(\mathrm{Pa})$ \\
\hline$P$ & Power (W). \\
\hline $\mathrm{PC}$ & Power converter. \\
\hline PCD & Power conditioner. \\
\hline$R$ & Resistance $(\Omega)$. \\
\hline SoC, SoC full & State of charge $(-)$. \\
\hline$T_{\mathrm{EM}}, T_{\mathrm{ICE}}$ & Torque $(\mathrm{N} \cdot \mathrm{m})$ \\
\hline$T$ & Transmission. \\
\hline$T_{S}$ & Timestep. \\
\hline$V, V_{\text {car }}, V_{w}$ & Velocity $\left(\mathrm{ms}^{-1}\right)$ \\
\hline$V$ & Voltage (V). \\
\hline$a, a_{w}$ & Acceleration $\left(\mathrm{ms}^{-2}\right)$. \\
\hline$d_{w}$ & Wheel diameter $(\mathrm{m})$ \\
\hline$e$ & Back electromotive force $(\mathrm{V})$. \\
\hline$g$ & Gravity $\left(\mathrm{ms}^{-2}\right)$ \\
\hline$i_{f}, i_{g}$ & Final gear ratio, gear ratio $(-)$ \\
\hline$m_{v}, m_{r}, m_{\text {fuel }}$ & Vehicle mass, rotating mass, fuel mass $(\mathrm{kg})$ \\
\hline$r_{w}$ & Wheel radius $(\mathrm{m})$ \\
\hline$u$ & Power split ratio. \\
\hline$x$ & State variable. \\
\hline$\alpha$ & Slope $(-)$ \\
\hline$\lambda$ & Slip ratio $(-)$ \\
\hline$\mu$ & $\begin{array}{l}\text { Adhesive coefficient, rolling resistance } \\
\text { coefficient }(-) \text {. }\end{array}$ \\
\hline$\eta$ & Efficiency $(-)$ \\
\hline$\omega_{\mathrm{EG}}, \omega_{t}$ & Rotational speed $\left(\operatorname{rad~s}^{-1}\right)$. \\
\hline \multicolumn{2}{|l|}{ Subscripts: } \\
\hline Exp & Experiment. \\
\hline Inv & Inversion. \\
\hline Model & Model. \\
\hline $\mathrm{OC}$ & Open circuit. \\
\hline$a$ & Aerodynamic. \\
\hline bat & Battery. \\
\hline br & Braking. \\
\hline$d$ & Driving. \\
\hline$f$ & Final. \\
\hline fr & Friction. \\
\hline fuel & Fuel. \\
\hline full & Full. \\
\hline$i$ & Indicated. \\
\hline
\end{tabular}




$\begin{array}{ll}k & \text { Instance. } \\ \max & \text { Maximum. } \\ \min & \text { Minimum. } \\ r & \text { Rolling resistance. } \\ \text { req } & \text { Request. } \\ \text { res } & \text { Total resistance. } \\ \text { system } & \text { System. } \\ t & \text { Transmission. } \\ w & \text { Wheel. } \\ \Sigma \text { bat } & \text { Total battery. }\end{array}$

\section{INTRODUCTION}

$\mathbf{H}$ $\mathrm{EV}$ is regarded as one of the effective solutions for the problem of energy shortage and demands to increase fossil fuel efficiency. The system with inherent advantages of improved fuel economy and reduced pollutant emissions has higher fuel efficiency and can achieve better performance than a conventional vehicle [1]-[3]. The presence of a reversible ESS offers new degrees of freedom to deliver power, possibility of engine downsizing, idle off, regenerative braking, and power assist that can increase the overall system efficiency [3]-[5].

HEV technology has been developed for many applications and different design combinations, such as series, parallel, and series-parallel. Series hybrid is the simplest kind of HEV and predominates urban transportation because of its outstanding transient performance and power response [1], [2], [6]. Low-noise operation due to the use of electric motors alone for traction offers benefits particularly in military operations, but larger drive system and multiple energy conversions counteract the overall efficiency of this architecture [7].

The design of HEV system architecture is complex, and the power management is complicated due to a high degree of control flexibility, as well as the use of nonlinear and multidomain components. Determination of design parameters and coordination of the multiple energy sources and converters to fully optimize its potential is cumbersome, time consuming, and expensive [4], [8]-[10]. Modeling of HEV configurations and interactions between its components becomes indispensable for rapid prototyping and analysis of HEVs.

In simulation, three main types of modeling methods exist: 1) steady-state method; 2) quasi-static method; and 3) dynamic method. The steady-state model is useful for system-level analysis and to assess long-term behavior of the vehicle [11]. Less computation time is required because it neglects all transient states and utilizes lookup tables to represent its experimental data [12]. An equivalent dynamic model added to a steady-state model forms a quasi-static model. It is usually used in global optimization of energy management [12]. This approach has been used to develop PSAT [13], ADVISOR [14], and QSS Toolbox [15], [16] for system analysis and design methods of HEV drive trains.

The dynamic model considers transient states and can study large load transients that occur during gear shifting or fast acceleration [11], [12], [17]. The model is more accurate and more complex causing an extended computation time, because it requires precise information on characteristic and environment of the system [8], [11], [16], [18]. It can give in-depth information about dynamic effects of sublevel components and facilitates performance measure to determine effective control laws and the optimum power plant or driveline combination [8], [10], [18]-[21]. Dynamic simulation approaches, such as EMR [22]-[24], PSIM [6], and V-Elph [20] simulation packages, are developed using this method.

In the simulation, driving cycle plays an important role in the optimization of vehicle control algorithm. Besides of standard driving cycles, a multitude of driving cycles can be created using a cycle generator based on the experimental data and statistics method [25], developing a traffic flow model [26], adding the standard driving cycles with topographic profiles [27], or collecting the real-world traffic data with onboard electronic equipments [28].

Even though the utilization of driving profile known a priori does not represent the real driving situations, this noncausal optimal solution can be used as benchmarks of the causal solution in development [16]. Studies prove that it is possible to integrate the previewed elements as controller inputs, via vehicle wireless technology [26], historical and online traffic information [26], [29], [30], or driving situation identifier [1], [31]. Identification of future obstacles, such as heavy traffic, steep grade, and even power demand, becomes easier using trip planning instruments, such as GIS and on-board GPS [32]-[36]. Approaches based on MPC can predict the future driving conditions efficiently for a sufficient long horizon [37], while a stochastic component of discrete time Markov chain can predict the future drive cycle by selecting a finite number of sampled power demands and vehicle speeds [17], [38].

HEV system models have been developed for diverse applications covering topics, such as optimal design problems [10], [15], [20], subsystems interactions [11], [15], controller development [7], [8], [29], [33], [39], [40], and system drivability [17]. Even if the models that can represent accurately the series HEV system exist, a model development of this system that focuses on a competition car meant to study its performance is not yet available.

In this paper, a series hybrid racing car equipped with an E/G set as range extender is studied. The Noao car is a result of collective work by experts and specialists of racing car application around Magny-Cours circuit [41], [42]. They use their expertise and experiences to build the car and heuristically define its control algorithm. A development of this car model using dynamic method is necessary to assess the performance of the car, generate its driving cycle, and evaluate its energy consumption and driving range during races.

The simulation has to include a module that emulates the behavior of the driver on pedal like in the real propulsion system [16]. The experimental data obtained from driving tests performed at Magny-Cours racing track are used to verify the accuracy of the model. Analysis of the track map and driving actions on certain zones of the circuit will be used to create a pattern of the driver behavior in function of distance.

This method will create a prediction tool to forecast inputs on car accelerator pedal position for other race tracks, obtain the driving schedule, and further determine energy consumption and battery SoC evolution of this car. As one of the 


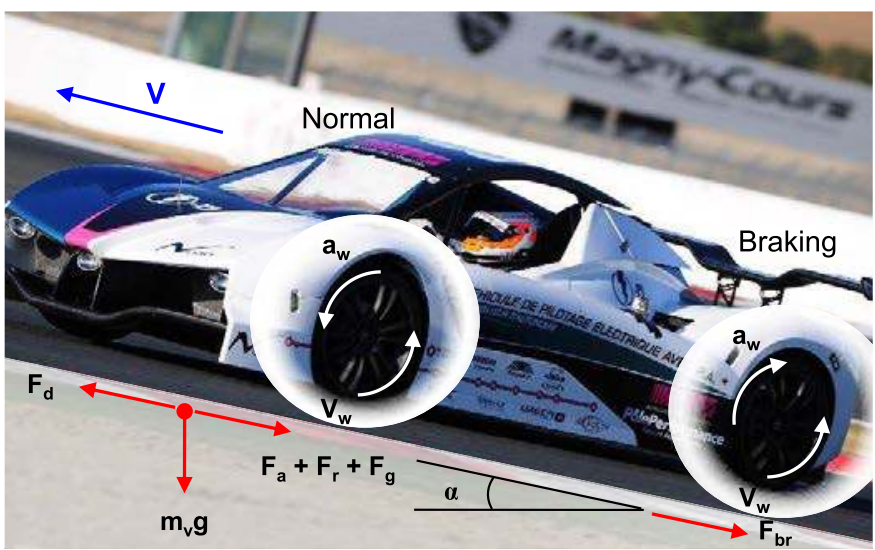

Fig. 1. Noao car.

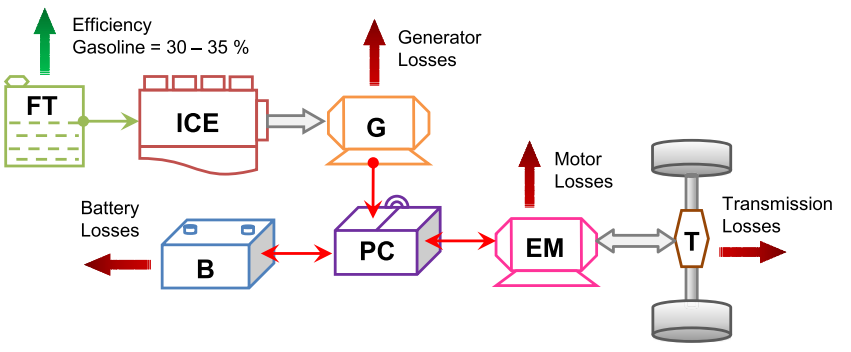

Fig. 2. Vehicle architecture.

objectives is to evaluate the distance, the car can complete before the charge depletes to its lower limit. This will maintain the battery power capacity, prolong the battery lifetime, and prevent the batteries from deteriorating dramatically due to deep discharge and high battery peak current [34], [40]. Moreover, without the need of car testing on the intended racing track, a database of racing driving schedules can be created using this method, which are useful to optimize the system.

The organization of this paper is as follows. Section II introduces the car, its components, and vehicle model. Section III covers the analysis of the driving cycle and the racing schedule prediction method, followed by the optimization of the control parameters. Discussion of the results is covered in Section IV, and finally perspectives and conclusion are given in Section V.

\section{Modeling}

\section{A. Vehicle Architecture}

The Noao car studied in this paper is a plug-in series hybrid electric racing car system developed by the Association des Entreprises Pole de la Performance Nevers Magny-Cours [41], [42], as shown in Fig. 1. The vehicle architecture is shown in Fig. 2 with arrows direction correspond to power flow in the system, and the vehicle components data are shown in Table I. Detailed characteristics of this car can be found in the website of the association [41].

The power train is composed of an electric traction motor (EM) with a PC, a battery pack (B) with a power electronic converter, and a set of an ICE and a generator $(\mathrm{G})$.

TABLE I

VEHICLE PARAMETERS

\begin{tabular}{ll} 
Vehicle mass, $m_{v}$ & $1200 \mathrm{~kg}$ \\
Front area, $A$ & $2 \mathrm{~m}^{2}$ \\
Drag coefficient, $C_{x}$ & 0.35 \\
Rolling resistance, $\mu$ & 0.012 \\
Wheel diameter, $d_{w}$ & $0.62 \mathrm{~m}$ \\
\hline
\end{tabular}

\section{Engine}

Generator

Electric motor

Battery

Transmission

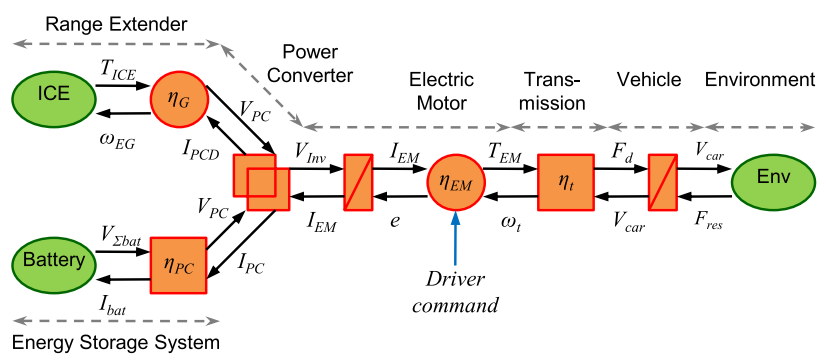

Fig. 3. EMR of the car system.

Three identical battery packs serve as the reversible ESS provide most of the energy needed for propulsion and energy recuperation during regenerative braking. The E/G set generates power for the range extender path. Both power sources are connected to an electric power bus, which is connected to the electric motor power converter.

\section{B. Vehicle Dynamics Model}

Model development of this system is implemented in a structured manner using EMR, modeled in simulation under MATLAB/Simulink software package, as shown in Fig. 3. EMR highlights energetic properties of a system based on action-reaction principle to organize the interconnection of subsystems according to the physical causality [22]-[24], [43]. Like in the real propulsion system, the driver command for acceleration and braking actions (pedal position) imposed to the system is taken as input of the power-train model [16].

The longitudinal dynamic derived from Newton's second law to determine the velocity of the vehicle is described in (1). The force to accelerate the vehicle and the rotating parts inside the vehicle is equal to the available driving force $F_{d}$, generated by prime mover minus the total resistance forces $F_{\text {res }}$ (Fig. 3). This power-train losses consist of the aerodynamic resistance $F_{a}$, the rolling resistance $F_{r}$, and the hill climbing force due to a nonhorizontal roads $F_{g}$. The hill climbing force $F_{g}$ of the vehicle is positive in uphill and negative if it is in downhill. For the Magny-Cours racing circuit, this element can be included in the analysis using the road elevation information available for the circuit in [42] and as shown in Fig. 4

$$
\left(m_{v}+m_{r}\right) \frac{d}{d t} V(t)=F_{d}(t)-\left(F_{a}(t)+F_{r}(t)+F_{g}(t)\right) .
$$




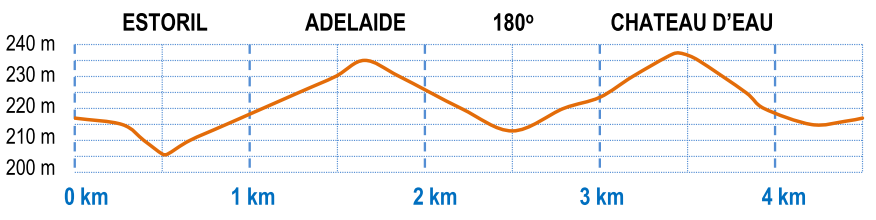

Fig. 4. Road elevation of the Magny-Cours circuit.

Equivalent mass of rotating parts $m_{r}$ from the electric motor down to the wheels for determining the inertial force to accelerate rotating parts inside this car [16] is detailed in (2) and added into the mass of the vehicle during normal driving. Calculation reveals $185-\mathrm{kg}$ rotational mass for a mechanical efficiencies $\eta_{f}$ and $\eta_{t}$ of 0.95 , final gear ratio $i_{f}$ of one, transmission ratio $i_{t}$ of 2.9 , and polar moment of inertia of $3.2 \mathrm{kgm}^{2}, 0.05 \mathrm{kgm}^{2}$, and $1.8 \mathrm{kgm}^{2}$, for the wheels $I_{w}$, propeller shaft $I_{p}$, and electric motor $I_{\mathrm{em}}$, respectively

$$
m_{r}=\left(\frac{1}{r_{w}}\right)^{2}\left[I_{w}+I_{p} \eta_{f} i_{f}^{2}+I_{\mathrm{em}} \eta_{t}\left(i_{f} i_{t}\right)^{2}\right] .
$$

During braking, to slow down the car, an external negative braking torque is applied to the wheel. It is the sum of the motor regenerative braking torque and the system supplementary mechanical braking torque [10]. Driving force $F_{d}$ is replaced by the braking force $F_{\mathrm{br}}$. The wheel linear speed becomes less than the vehicle speed and creates an opposite force to the forward motion. In this phase, the traction force caused by the friction between the road surface and the tire surface is the weight dynamic transfer times the adhesive coefficient $\mu$ [10], [44] expressed in (3). The adhesive coefficient $\mu$ is in function of slip ratio $\lambda$ under certain tire condition and road conditions

$$
\left(m_{v}+m_{r}\right) \frac{d V}{d t}=\mu(\lambda) m_{v} g-\left(F_{a}+F_{r}+F_{g}\right) .
$$

As for the system studied in this paper, the driving test is performed on a dry asphalt track. At acceleration to braking transition shown in Fig. 1, the rotating mass accelerates in the inverse direction $\left(a_{w}\right)$ of the vehicle linear speed $V$, resulting in less dynamic weight transfer to the vehicle during this phase.

Lateral motion equation to calculate lateral force is not included in this paper because the exact steering angle measurements are not available. A modeling of yaw rate effect for a sport series HEV can be found in [45].

\section{Battery Model}

The primary energy source of this system is the battery. There are three identical lithium-ion batteries with $520 \mathrm{~V}$ nominal voltage installed in this car. The batteries are identical to each other for having the same $\mathrm{SoC}$ performance. They are connected in series and placed in the vehicle to balance the weight distribution of the car [41], [42]. The model of the battery is represented by (4)-(7). $P_{\text {bat }}$ is the power to the battery, which is positive during discharge and negative if it is recharged. SoC is defined as the index of the current energy available from a battery compared with the battery capacity $C_{t}$.
The battery open-circuit voltage $V_{\text {oc }}$ and resistance $R$ are in function of SoC, and the voltage of the battery package $V_{\Sigma \text { bat }}$ is the cell voltage $V_{\text {bat }}$ times the number of cells in the battery pack

$$
\begin{aligned}
P_{\text {bat }}= & I_{\text {bat }} \cdot V_{\Sigma \text { bat }} \\
\text { SoC }= & S_{\text {SoC }} \text { full }-\frac{\int I_{\text {bat }} \cdot V_{\Sigma \text { bat }}}{C_{t}} \\
V_{\mathrm{OC}}= & -1.031 \exp (-35 \mathrm{SoC})+3.685+0.2156 \mathrm{SoC} \\
& -0.1178 \mathrm{SoC}^{2}+0.321 \mathrm{SoC}^{3} \\
V_{\text {bat }}= & V_{\mathrm{OC}}-R \cdot I_{\text {bat }} .
\end{aligned}
$$

\section{E/G Model}

The range extender energy source is the E/G set. The ICE is a three-cylinder direct-injection gasoline engine of $1.0 \mathrm{~L}$, with $50-\mathrm{kW}$ nominal power. It is coupled to a generator of $54-\mathrm{kW}$ nominal power at $4500 \mathrm{r} / \mathrm{min}$ with a maximum combined efficiency of 0.275 .

The fuel consumption at a specific operational point of the engine is calculated using 0-D single-zone thermodynamic model of the ICE in function of the engine speed and load derived from [46]

$$
\eta_{i}=\frac{\int-P d V}{m_{\text {fuel }} \mathrm{LHV}}
$$

where $\eta_{i}$ is the fuel indicated efficiency, defined as the ratio between the work transfer to the piston due to the in-cylinder pressure $P$ and the fuel theoretical available energy, $P_{\text {fuel }}$. LHV is the lower heating value of the fuel used (Gasoline $44 \mathrm{MJ} \mathrm{kg}^{-1}$ ) and $m_{\text {fuel }}$ is the fuel consumption for a displaced volume $d V$.

The fuel effective power $P_{\text {ICE }}$ in (9) is equal to fuel indicated power minus friction power $P_{\mathrm{fr}}$, which produces the effective torque $T_{\mathrm{ICE}}$ at an engine generator speed $\omega_{\mathrm{EG}}$

$$
P_{\mathrm{ICE}}=\eta_{i} P_{\text {fuel }}-P_{\mathrm{fr}}=T_{\mathrm{ICE}} \cdot \omega_{\mathrm{EG}} .
$$

Based on EMR in Fig. 3, the total power $P_{\text {req }}$ delivered for traction at transmission is represented by the electric motor torque $T_{\mathrm{EM}}$ times its transfer speed from transmission $\omega_{t}$, as shown in (10). The electric motor is a three-phase star connected bidirectional permanent magnet synchronous motor that acts as motor for traction and generator during deceleration. Inefficiencies of this machine are caused by its stator copper winding resistances and other electromagnetic dissipations

$$
P_{\text {req }}=\eta_{\mathrm{EM}} P_{\mathrm{EM}}=T_{\mathrm{EM}} \cdot \omega_{t} .
$$

The power transmitted by the electric motor $P_{\mathrm{EM}}$ is supplied by the battery and the engine with losses at the power converter and the generator in function of inverter voltage $V_{\text {Inv }}$ and the motor current $I_{\mathrm{EM}}$. In this model, the components efficiencies $\eta_{\mathrm{EM}}, \eta_{G}$, and $\eta_{i}$ are simulated using lookup tables in function of torque and rotational speed. Power converter efficiency $\eta_{\mathrm{PC}}$ and transmission efficiency $\eta_{t}$ are considered constant

$$
P_{\mathrm{EM}}=P_{\mathrm{ESS}}+P_{\mathrm{EG}}=\eta_{\mathrm{PC}} P_{\mathrm{bat}}+\eta_{G} P_{\mathrm{ICE}} .
$$


The amount of power given by each sources is determined by the control strategy. A good control strategy should give an optimal solution over the applied driving cycles, have less power losses, low consumption, can prevent battery degradation, and can give the requested power efficiently.

\section{Control Strategy}

The control strategy for HEV systems can be based on rule-based (RB) method or optimization method. The $\mathrm{RB}$ control strategy is easy to implement for a realtime supervisory control of power flow in a hybrid drive train [1], [4], [26], [27], [29]. It can achieve near optimal solution, but cannot be easily implemented to another vehicle or driving cycle due to lack of formal optimization and generalization, thus may fail to fully exploit potentials of $\mathrm{HEV}$ architecture [5], [26], [29], [47].

The optimization method can provide generality and reduce heavy tuning of control parameters [48]. Its task is to minimize a cost function in real time or offline based on the vehicle and component parameters, as well as the performance expectations of the vehicle [47]. Real-time optimization method minimizes a cost function at each instant that depends only upon the system variables at the current time, which have been developed using the system's past information. It has limits on knowledge of future driving conditions and the electrical path self-sustainability causing the solution not to be global optimal [47]-[49].

Global optimization approach can find a global optimum solution over a fixed driving cycle and known future driving conditions to determine power distribution of each system, which is unsuitable for a real-time vehicle control [48]-[51]. It requires heavy computation and is usually used for offline simulation applications as a design tool to analyze, assess, and adjust other control strategies for online implementation [2], [47], [49]. One of the interests of this paper is to study how to implement this approach offline to optimize the system power distribution using a predicted driving cycle.

A control method suitable for a plug-in HEV is a depletion of the battery charge from its higher limit to its lower limit throughout a driving cycle to achieve best efficiency [26]. For a track competition car, the driving cycle will be the circuit driving schedule on a number of laps. The control strategy of this car consists of always putting the engine in mode to assist the car propulsion during races for longer autonomy.

As can be observed from the vehicle architecture in Fig. 2, the generator transforms mechanical energy from the engine to electricity to recharge the battery or assist the motor for propulsion. The load torque only concerns electric motor torque, therefore the E/G set can operate at its optimal working points at all times.

\section{A. Actual RB Control Method}

In the studied system, the actual control strategy defines battery current and $E / G$ power generation according to the command input from accelerator pedal, as shown in Fig. 3. The existing RB control strategy is used to determine power repartition for the propulsion of the car.
During full throttle, i.e., maximum pedal angle, the algorithm will supply a predefined maximum power to wheels by compensating the drop of the battery charge with the power produced by the range extender. Operation of battery is controlled so that current operates within safe limits to prevent high battery peak current. This control strategy has been used to validate the simulation model.

\section{B. Optimization Using DP}

The optimization of this car system has been made in [52] to split power between the power sources using DP approach and will be used to adjust control thresholds of the car. DP can solve the optimal control of nonlinear time-variant constrained discrete-time approximations of continuous-time dynamic models of HEV. It can achieve absolute optimal fuel consumption for different system configurations, but it needs all of the future conditions of inputs to be known a priori [27], [50].

DP is not implementable in real vehicle due to the preview nature and heavy computation requirement, but it can be used for offline simulations and to compare performance of a real-time controller [4], [26], [53]. Stochastic DP has been implemented in [17] and [38] to be used in a real vehicle by selecting a finite number of sampled power demands defined using Markov-chain model.

Through optimization using quasi-static model formulated for this series hybrid car, the system is optimized to achieve minimum system losses

$$
J=\int_{0}^{T} \frac{P_{\text {fuel }}}{P_{\mathrm{EG}}} d t+\int_{0}^{T} \frac{P_{\mathrm{bat}}}{P_{\mathrm{ESS}}} d t .
$$

The system optimization is subjected to its physical constraints, (13)-(15). The maximum power that can be delivered by the range extender is $P_{\mathrm{EG}}{ }_{\max } \cdot P_{\mathrm{ESS}}$ min is the limit of the power recuperation and $P_{\mathrm{ESS}}$ max is the maximum power limitation of the battery

$$
\begin{aligned}
P_{\mathrm{EM}}(t) & =P_{\mathrm{ESS}}(t)+P_{\mathrm{EG}}(t) \\
0 & \leq P_{\mathrm{EG}}(t) \leq P_{\mathrm{EG}_{\max }} \quad \forall t \in[0, T] \\
P_{\mathrm{ESS}_{\min }} & \leq P_{\mathrm{EM}}(t)-P_{\mathrm{EG}}(t) \leq P_{\mathrm{ESS}_{\max }} \quad \forall t \in[0, T] .
\end{aligned}
$$

The time-variant model takes battery SoC as its state variable $x$ at each instance $k$ and at power split ratio $u$. $N$ is the number of the timesteps $T_{S}$ and $L_{N}$ is the length of the problem. The initial state $x_{0}$ is the initial SoC and final SoC will be taken as the final state $x_{N}$

$$
\begin{aligned}
x_{k+1} & =f_{k}\left(x_{k}, u_{k}\right)+x_{k} \quad k=0,1, \ldots, N-1 \\
x_{k} & \in\left[x_{0}, x_{N}\right] \\
N & =\frac{L_{N}}{T_{s}}+1 .
\end{aligned}
$$

\section{DRiving Cycle Model DeVelopment}

As race application is different from other vehicles applications, this car needs a driving cycle database of its own for optimization purpose. This is because the existing standard 


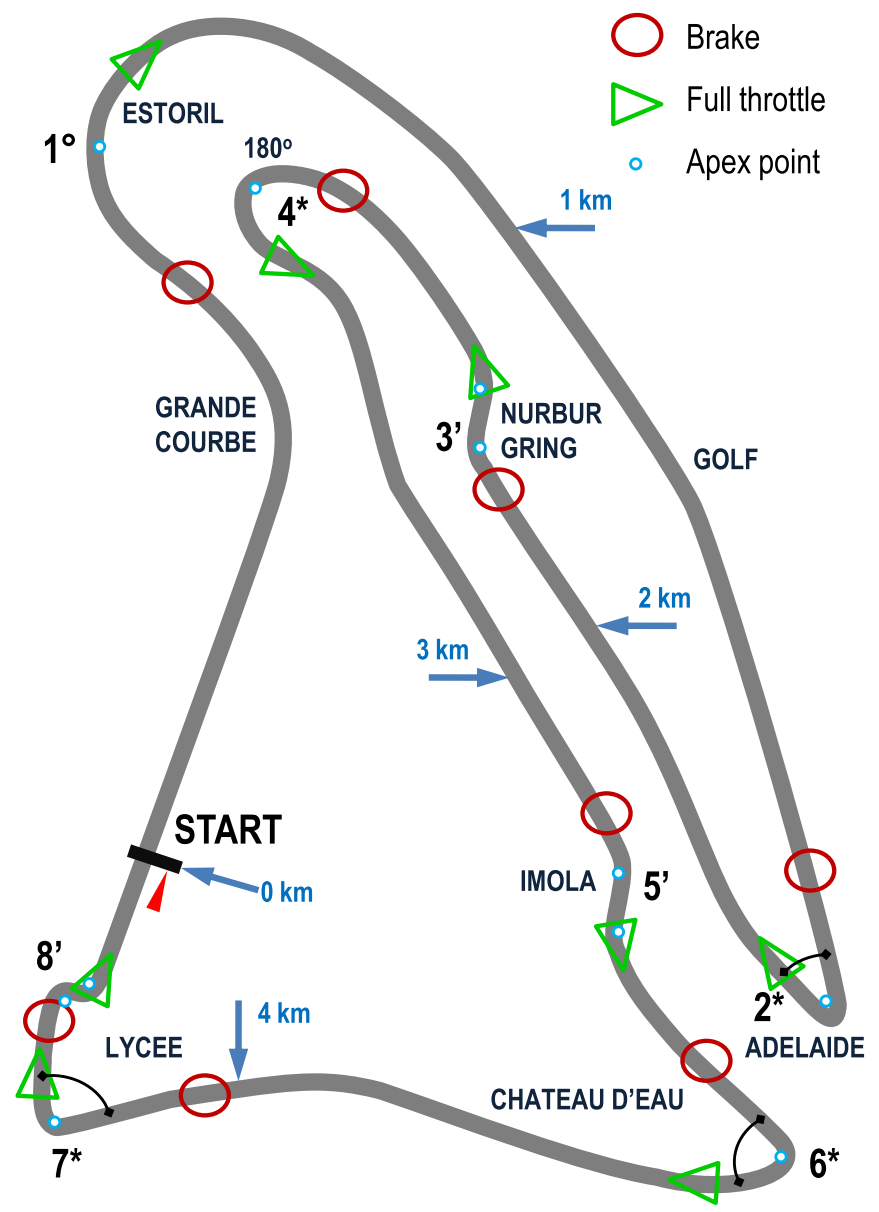

Fig. 5. Map of the Magny-Cours main circuit with eight turning zones.

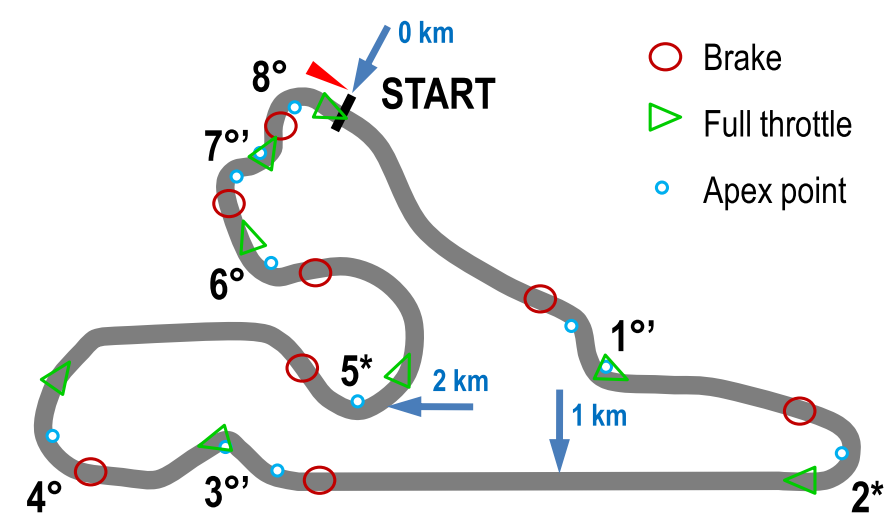

Fig. 6. Map of the smaller Magny-Cours circuit with eight turning zones.

driving cycles do not correspond to the design, and its driving style is not the same like any passenger car. This car has been tested on the real track of Magny-Cours Grand Prix racing circuit and a smaller circuit at site. The driving test results are then analyzed for further improvement of this car. A driving pattern is deducted by referring to the conducted experimental results and observation on drivers actions on pedal at particular locations of the circuit. However, this driving cycle prediction method can only be realized if there is a good vehicle dynamic model of the studied system.

\section{A. Magny-Cours Circuits Map Analysis}

The Grand Prix circuit is shown in Fig. 5, which is 4411-m long and has eight cornering zones that can be distinguish in three categories: 1) half-turn; 2) hairpin; and 3) chicane. From the starting point, the zones are numbered from one to eight with marks corresponding to the turning type. Zone 1 and 4 are the half-turn, zone 2, 6, and 7 are the hairpin, and zone 3 , 5 , and 8 are the chicane. The characteristics of these zones are classified in Table II, but due to a tight corner of the turning zone 4 , it is classified under the hairpin turning type because its turning angle is more than $90^{\circ}$.

Distance from starting point is the distance of the location where braking and accelerating actions are executed by the pilot and marked in the circuit map. The apex point is the closest point to the inside of a corner and usually will be hit by the car when turning.

The map of the smaller club circuit is shown in Fig. 6, also with eight cornering zones and a length of $2530 \mathrm{~m}$. On this circuit, appear new category of cornering zone, which is a combination of the half turn and the chicane at zone 1,3 , and 7 . These zones have a form of the chicane, but with tighter angle and bigger gap between its apex points. Zone 2 and 5 are the hairpin type and zone 4, 6, and 8 are the half-turn type, and the details are given in Table II.

\section{B. Drivers Action Analysis}

Langari and Won [1] integrate a driving style identifier in the energy management agent and classify three types of driving styles: 1) calm driving; 2) normal driving; and 3) aggressive driving based on average acceleration and its range specific standard deviation. In our case, driving style will be aggressive driving style. The driver behavior depends on many factors and cannot be defined with an exact mathematical model, and it will not represent the real driving during competition races. However, this information is useful for the construction of the driving cycle and the system maximum energy requirement.

The actions on the accelerator pedal are shown in Fig. 7 for the bigger circuit and in Fig. 8 for the small circuit. The pedal acts on speedup and slow down of the car with a minimum angle of $0^{\circ}$ to maximum throttle angle that is tuned at $83^{\circ}$ in the first test and at $53^{\circ}$ at the second test. Each braking action corresponds to cornering zones of the circuit; we can observe that braking is brief and rapid (2-3s) at the chicane turning zone. In addition, the pedal is released more and longer (4-6 s) at the hairpin corners than the half-turn corner (3-4 s). Braking action like in the half-turn corner is doubled at the combined half-turn chicane zone.

There are two apex points at the chicane zone: the car will brake until it arrives at the first apex and start stepping on the accelerator and reaches full throttle at the second apex. There is only one apex point at other cornering types that are specified by a long braking before entering the corner and the car starts to accelerate just after passing the apex point.

Analysis of the driver's behavior comprises only the pedal action; the analysis of the driver on steering wheel is not included because the exact information of this element is not available from the experiments. 
TABLE II

Magny-Cours Circuits Turning Zones Characteristics of the Grand Prix Circuit and the Club Circuit

\begin{tabular}{|c|c|c|c|c|c|c|c|}
\hline \multirow[b]{2}{*}{ Zone } & \multicolumn{3}{|c|}{$\begin{array}{l}\text { Grand Prix Circuit } \\
\text { Distance from start } \pm 5 \mathrm{~m}\end{array}$} & \multicolumn{4}{|c|}{ Small Club Circuit } \\
\hline & Braking $(\mathrm{m})$ & Full throttle $(\mathrm{m})$ & Turn type & Zone & Braking $(\mathrm{m})$ & Full throttle (m) & Turn type \\
\hline $1^{\circ}$ & 445 & 570 & half turn & $1^{\circ \prime}$ & 300 & 440 & half turn chicane \\
\hline $2^{*}$ & 1850 & 1755 & hairpin & $2^{*}$ & 615 & 715 & hairpin \\
\hline $3^{\prime}$ & 2190 & 2300 & chicane & $3^{\circ \prime}$ & 1255 & 1395 & half turn chicane \\
\hline $4^{*}$ & 2490 & 2650 & hairpin & $4^{\circ}$ & 1530 & 1600 & half turn \\
\hline $5^{\prime}$ & 3160 & 3265 & chicane & $5^{*}$ & 1910 & 2030 & hairpin \\
\hline $6^{*}$ & 3460 & 3585 & hairpin & $6^{\circ}$ & 2255 & 2335 & half turn \\
\hline $7^{*}$ & 4055 & 4205 & hairpin & $7^{\circ \prime}$ & 2370 & 2430 & half turn chicane \\
\hline $8^{\prime}$ & 4255 & 4315 & chicane & $8^{\circ}$ & 2475 & 2515 & half turn \\
\hline
\end{tabular}
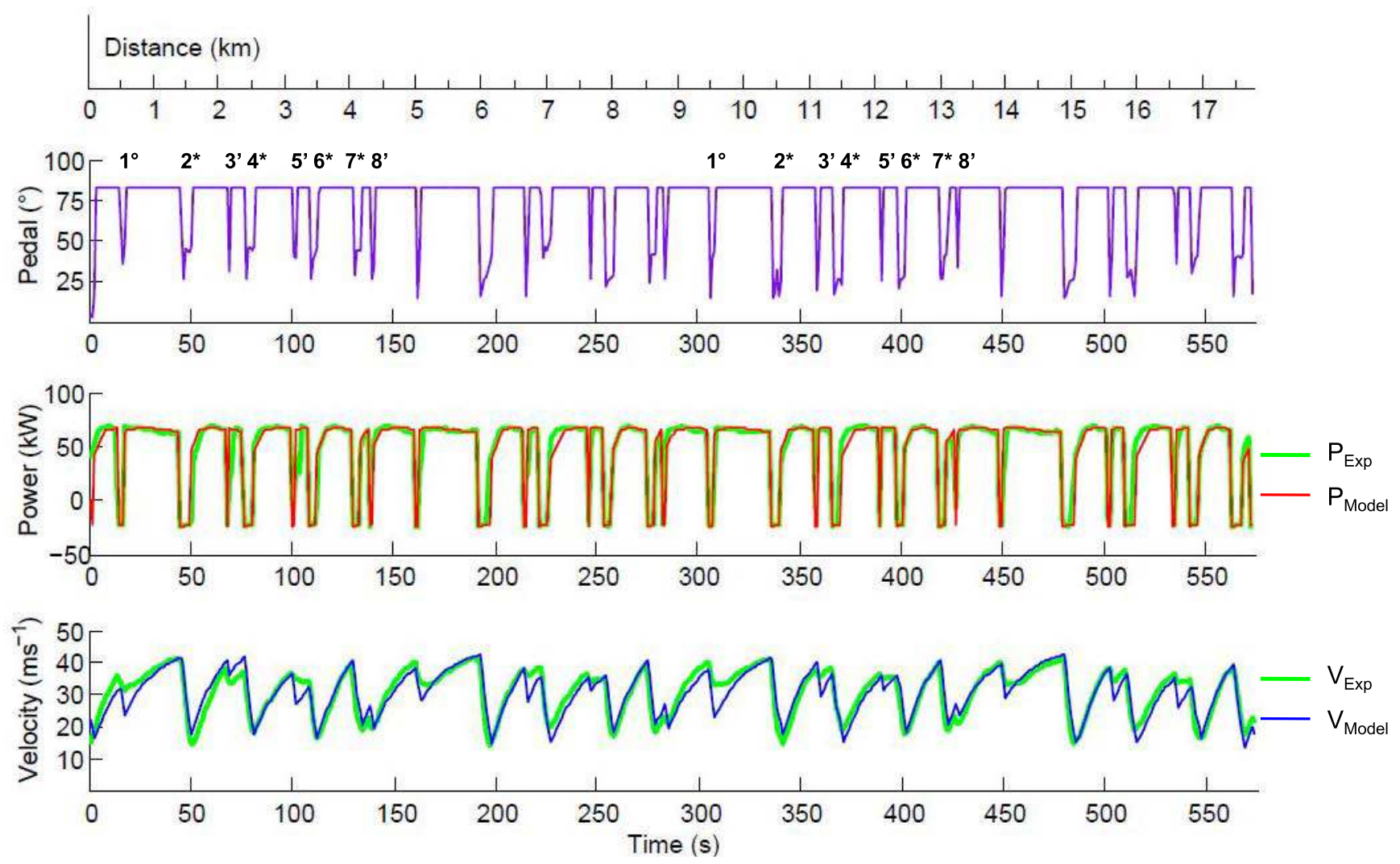

Fig. 7. Comparison of the model with the results from the experiment for the Grand Prix circuit.

\section{RESUlTS COMPARISON}

\section{A. Model Validation}

The experimental results of this car are obtained through driving tests conducted on the Magny-Cours circuits. The test on the main circuit has been carried out for four laps of the track and 0.54-0.37 SoC depletion. The profile of power at wheels and car velocity are shown in Figs. 7 and 8 for the experiment and the model. The model is quite accurate and follows closely the experiment for the power profile but it is less precise for the speed profile with errors mostly at the cornering zones of the circuit.

This is because the vehicle dynamic model used in this paper is a single-wheel model and it does not consider the effect of yaw angle when turning. That is why there are discrepancies in the results of the velocity profile due to yaw motion, steering angle, skid effect, and tire lateral forces. However, the tire longitudinal force is related particularly to power flow of the propulsive power, resulting in a nearly same profile between the model and the experiment.

The power profile resembles the profile of the pedal with a maximum power of $70 \mathrm{~kW}$ at full throttle and a regenerative power of $25 \mathrm{~kW}$ when braking on the main circuit. Under this condition, the maximum velocity that can be attained by the car is $42 \mathrm{~ms}^{-1}\left(151.2 \mathrm{kmh}^{-1}\right)$. The performance of a car depends largely on the available propulsion maximum power. It is expected that if the power limit is higher, the car will have more traction force, as shown in (1), resulting 


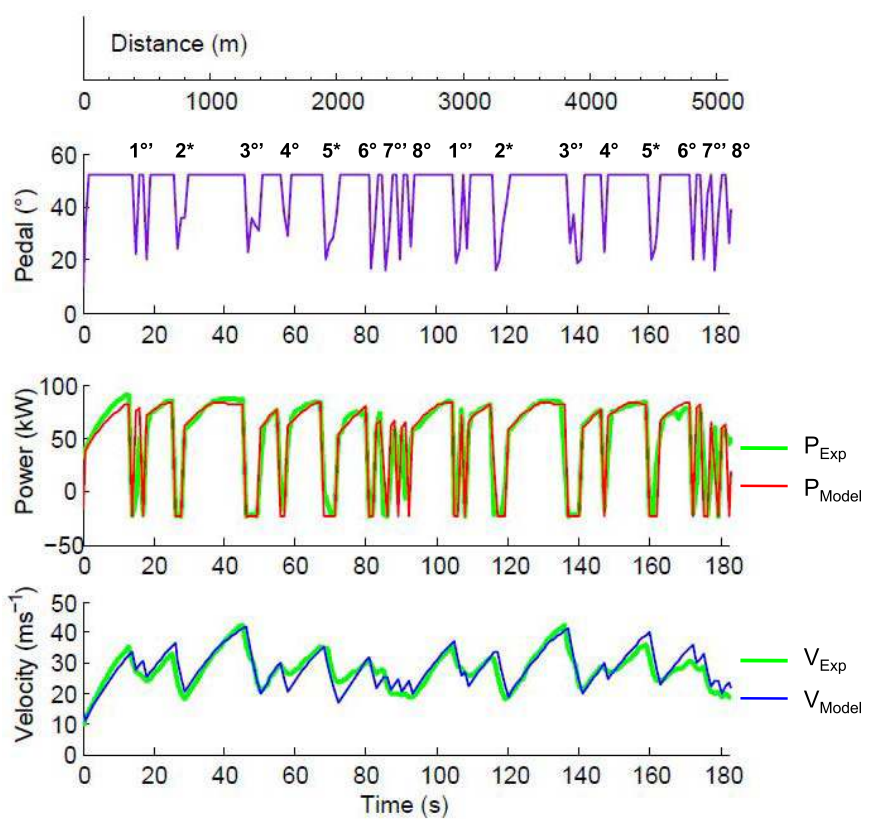

Fig. 8. Comparison of the model with the results from the experiment for the small club circuit.

in a shorter drivetime and a higher mean velocity, i.e., better performance of the car but no longer the same driving cycle.

As can be observed in the results for the smaller circuit in Fig. 8, the maximum power for this driving test is limited to $86 \mathrm{~kW}$. Two laps of the circuit discharge the battery from SoC 0.37 to 0.3 . As deceleration is limited by the tire adherence, the recuperation limit is the same for both cases. There are fewer occasions for long acceleration and this circuit is more difficult with its successive corners.

This car can reach a maximum speed of $42 \mathrm{~ms}^{-1}$ from $18 \mathrm{~ms}^{-1}$ in $17 \mathrm{~s}$, which is faster than it can do at the bigger circuit, which is from $30 \mathrm{~ms}^{-1}$ in $25 \mathrm{~s}$. In addition, a faster SoC diminution with a rate of 0.0138 per $\mathrm{km}$ on the club circuit compared with only 0.0096 per $\mathrm{km}$ for the Grand Prix circuit. At these rates, if battery SoC trajectory is limited to deplete from 0.9 to 0.3 , the distance that can be completed at the small circuit will be only 43.5 and $62.5 \mathrm{~km}$ on the Grand Prix racing track.

A compromise between its performance and driving range can be made by knowing the energy consumption rate of this car at a particular driving circuit, to prevent the battery from over discharged during races.

In this paper, two racing tracks with different power limits have been analyzed and simulated. In addition, it can be concluded that for a different racing track, driver's pedal action on a particular zone type will be the same. In spite of the pedal maximum tuned value, the driver's aggressivity when pressing pedal will provide information of the power profile if simulated using a predefined maximum power.

The circuit map can provide information on the difficulty level of the circuit and the occasions this hybrid car will have for energy recuperation and acceleration. To obtain a new driving cycle, simulation and discretization have to be
TABLE III

Results COMPARISON OF THE THREe CONTROL STRATEGIES: Actual RB Method, DP Optimization, And the Adjusted PARAMETERS FOR REAL-TIME CONTROL

\begin{tabular}{lccc} 
& $\begin{array}{c}\text { Actual } \\
\text { RB method }\end{array}$ & $\begin{array}{c}\text { DP } \\
\text { optimization }\end{array}$ & $\begin{array}{c}\text { Adjusted } \\
\text { parameters }\end{array}$ \\
\hline SOC Initial & 0.54 & 0.54 & 0.54 \\
SOC Final & 0.37 & 0.37 & 0.40 \\
$\Sigma P_{E M}(\mathrm{MWs})$ & 32.448 & 32.448 & 32.795 \\
\hline & & & \\
$\Sigma P_{E G}(\mathrm{MWs})$ & 20.894 & 20.513 & 20.320 \\
$\Sigma P_{\text {fuel }}(\mathrm{MWs})$ & 84.194 & 76.099 & 82.710 \\
$\Sigma m_{\text {fuel }}(\mathrm{kg})$ & 1.914 & 1.729 & 1.880 \\
Average $\eta_{E G}(-)$ & 0.2484 & 0.2696 & 0.2457 \\
\hline & & & \\
$\Sigma P_{E S S}(\mathrm{MWs})$ & 11.554 & 11.935 & 12.475 \\
$\Sigma P_{\text {bat }}(\mathrm{MWs})$ & 11.599 & 11.769 & 11.889 \\
Average $\eta_{E S S}(-)$ & 0.9961 & 1.0141 & 1.0493 \\
\hline & & & \\
Average $\eta_{\text {system }}(-)$ & 0.3387 & 0.3693 & 0.3467 \\
\hline
\end{tabular}

executed part by part according to braking and accelerating actions to match the drivetime with the distance completed.

As perspective, the precision of the generated driving schedules can be improved using a more detailed model, such as single-track or two-track vehicle dynamics model. Utilization of these models and analysis of a reference track and its curvature line can be used to predict steering angle that will taken by the driver. Nevertheless, the model used in this simulation using pedal as input can determine the maximum performance of the car, its drivetime, driving range, SoC depletion, and energy consumption that are useful to design a better energy management for the system.

\section{B. Control Strategies Modification}

From this point on, the optimization and its study for realtime control will only concern the car operation on the Grand Prix racing circuit. The comparison between data from the experiment, DP optimization results, and the model with the modified control thresholds are shown in Table III and Fig. 9.

In the actual car, a uniform E/G power repartition is imposed along the battery SoC evolution with a slight augmentation in function of SoC depletion, as shown in Fig. 9. About half of the power request is supplied by the E/G with a threshold of $20-39 \mathrm{~kW}$ during braking and accelerating, respectively. Through DP optimization, the E/G power is chosen to be, $40 \mathrm{~kW}$, maximum when the $\mathrm{SoC}$ is more than 0.5 , and only $35 \mathrm{~kW}$ when the SoC drops under 0.5 with sometimes E/G power is below $20 \mathrm{~kW}$ during braking to improve the system efficiency. This choice is probably caused by the resistance of the battery, which is different in function of SoC and different during recharge and discharge of the battery.

In Table III, average E/G efficiency, $\eta_{\mathrm{EG}}$ is simply taken as total power delivered at electric motor by the range extender $P_{\mathrm{EG}}$ divided by total theoretical power produced by the fuel $P_{\text {fuel }}$, composed of the fuel indicated efficiency $\eta_{i}$, inefficiency 

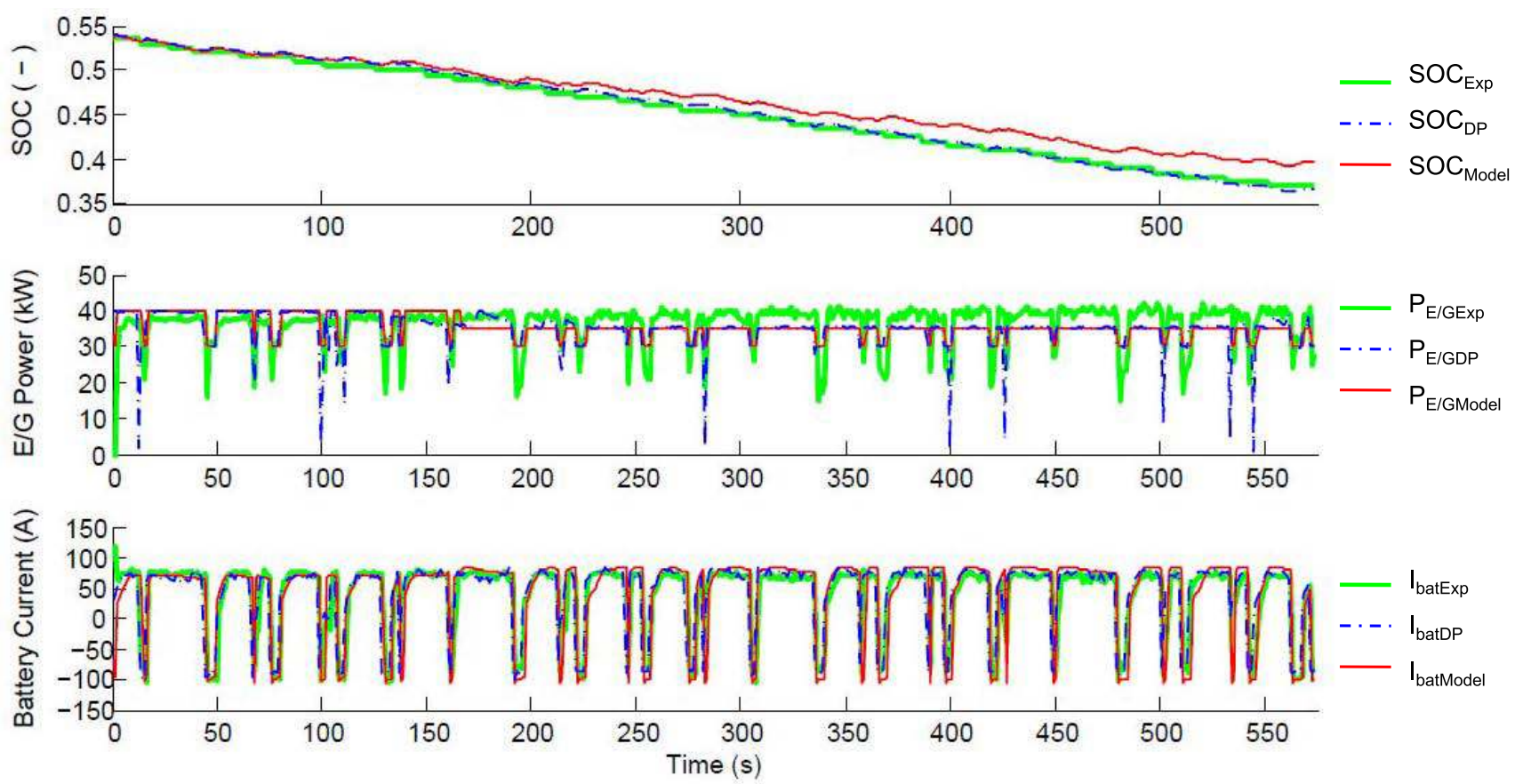

Fig. 9. Comparison of SoC evolution and the systems power distribution for the experiment, optimization using DP, and the adjusted controller.

due to engine friction, and the generator efficiency $\eta_{G}$. Same assumption is made to the average ESS efficiency, $\eta_{\mathrm{ESS}}$, obtained by simply calculating $P_{\mathrm{ESS}} / P_{\text {bat }}$. ESS component comprises of the battery and the power converter. This value becomes more than one because the battery absorbs the regenerative power and E/G power during braking phase. For the system efficiency, it is calculated as the sum of powers to the electric motor divided by the sum of powers provided by battery, fuel, and regenerative braking.

Before applying the modification of the control threshold onto the real vehicle, the adjusted parameters are simulated in the model according to the results obtained by DP. Interpretation of the results and simplification have to be done in order to be able to implement the new parameters in function of the requested power and SoC. Therefore, from the observation of the requested power from regenerative braking to traction, if $\mathrm{SoC}$ is more than 0.5 , the $\mathrm{E} / \mathrm{G}$ should deliver from 30 to $40 \mathrm{~kW}$, and then 30 to $35 \mathrm{~kW}$ if SoC is less than 0.5 .

By simulation using the interpreted DP results in the model, modification of the thresholds will cause a higher fuel consumption of $1.88 \mathrm{~kg}$ but a better system efficiency (0.3467), as can be observed in Table III. This is because more power from the $\mathrm{E} / \mathrm{G}$ will be delivered to the battery during regenerative braking, and SoC depletes slower to 0.4 , whereas it was 0.37 before in the existed control strategy. No specific pattern can be deduced from DP for the E/G power when it is below $20 \mathrm{~kW}$ in function of the requested power or SoC.

The fuel consumption is lower, $1.88 \mathrm{~kg}$ compared with its actual control that consumes $1.914 \mathrm{~kg}$, but less optimal than that one calculated using DP, which is $1.729 \mathrm{~kg}$. Nevertheless, the driving range of this car using the adjusted parameter will be longer for a targeted SoC drop from 0.9 to 0.3 . Battery current comparison shows nearly the same evolution for the three cases; all are within the currents limits defined for this battery.

This paper shows how to optimize the system operation by interpreting the results from DP for a fixed driving cycle with known future condition. Even if the exact future conditions are known, DP results cannot be directly applied for the real-time controller of the car to split power because a slight change of the car operation may cause the whole system to be not optimal.

In this paper, the optimization is performed only on one driving cycle. It is expected that if it is to be applied on the smaller circuit with the same power limit, the system operation will be less efficient. The control strategy has to be tested on different driving cycles, and prediction method discussed in this paper will allow to create a multitude driving schedules for different racing tracks and performances. Finally, the decision will be whether to use a specifically designed control strategy for a particular case or to design an optimal control for all driving cycles.

\section{CONCLUSION}

A series hybrid racing car system is modeled dynamically using EMR. Single-wheel vehicle dynamics model is utilized for simulation and shows acceptable accuracy with race car real behavior on the studied racing circuits. Comparison between actual RB control strategy, DP optimization done for this car, and developed model with adjusted control thresholds based on DP results shows an improvement on system efficiency compared with its actual power split control. For the same velocity profile and performance, the car with adjusted control can achieve longer autonomy over a targeted SoC depletion. An analysis on pattern of pedal action on 
particular zones in function of its distance is presented for two different racing circuits and will be used as a prediction method to forecast drivers pedal actions on other racing tracks. This method is useful to obtain velocity profile and power profile of the car for determined power limits and create a multitude of driving cycles for its optimization in terms of fuel consumption, system efficiency, drivetime, or SoC trajectory. In the future, the model can also be used to redesign the parameters of the car components for a better performance or driving range. Outside racing car application, this method can be extended to predict driving cycles of busses or courier vehicles where the constraints will be similar; aggressive driving style, nearly fixed pathway, and a limited time to finish the circuit. The implementation will be different according to vehicle type, but the concepts of input utilization will be the same to predict driving cycle and energy utilization.

\section{ACKNOWLEDGMENT}

The authors would like to thank the Burgundy Region Council, Malaysian Government, and the University of Technology Malaysia.

\section{REFERENCES}

[1] R. Langari and J. Won, "Intelligent energy management agent for a parallel hybrid vehicle-Part I: System architecture and design of the driving situation identification process," IEEE Trans. Veh. Technol., vol. 54, no. 3, pp. 925-934, May 2005.

[2] J. Gao, G. Zhu, E. Strangas, and F. Sun, "Equivalent fuel consumption optimal control of a series hybrid electric vehicle," J. Automobile Eng., vol. 8, no. 223, pp. 1003-1018, Aug. 2009.

[3] K. Rajashekara, "Present status and future trends in electric vehicle propulsion technologies," IEEE J. Emerging Sel. Topics Power Electron., vol. 1, no. 1, pp. 3-10, Mar. 2013.

[4] C.-C. Lin et al., "Integrated, feed-forward hybrid electric vehicle simulation in SIMULINK and its use for power management studies," Autom. Res. Center, Univ. Michigan, Ann Arbor, MI, USA, Tech. Rep. 200101-1334, 2001.

[5] L. Serrao, S. Onori, and G. Rizzoni, "A comparative analysis of energy management strategies for hybrid electric vehicles," J. Dyn. Syst., Meas., Control, vol. 133, no. 3, pp. 031012-1-031012-9, May 2011.

[6] S. Onoda and A. Emadi, "PSIM-based modeling of automotive power systems: Conventional, electric, and hybrid electric vehicles," IEEE Trans. Veh. Technol., vol. 53, no. 2, pp. 390-400, Mar. 2004.

[7] M. Gokasan, S. Bogosyan, and D. Goering, "Sliding mode based powertrain control for efficiency improvement in series hybrid-electric vehicles," IEEE Trans. Power Electron., vol. 21, no. 3, pp. 779-790, May 2006.

[8] B. K. Powell, K. E. Bailey, and S. R. Cikanek, "Dynamic modeling and control of hybrid electric vehicle powertrain systems," IEEE Control Syst. Mag., vol. 18, no. 5, pp. 17-33, Oct. 1998.

[9] J. Park, and Y. Park, "Real-time powertrain control strategy for seriesparallel hybrid electric vehicles," Hyundai Motor Co. Jahng-Hyon Park Hanyang Univ., Seoul, South Korea, Tech. Rep. 2007-01-3472, Aug. 2007.

[10] D. W. Gao, C. Mi, and A. Emadi, "Modeling and simulation of electric and hybrid vehicles," Proc. IEEE, vol. 95, no. 4, pp. 729-745, Apr. 2007.

[11] M. Amrhein and P. T. Krein, "Dynamic simulation for analysis of hybrid electric vehicle system and subsystem interactions, including power electronics," IEEE Trans. Veh. Technol., vol. 54, no. 3, pp. 825-836, May 2005.

[12] C. C. Chan, A. Bouscayrol, and K. Chen, "Electric, hybrid, and fuelcell vehicles: Architectures and modeling," IEEE Trans. Veh. Technol., vol. 59, no. 2, pp. 589-598, Feb. 2010.

[13] A. Rousseau, S. Pagerit, and D. Gao, "Plug-in hybrid electric vehicle control strategy parameter optimisation," Int. Electr. Veh. Symp., vol. 23, pp. 1-14, Dec. 2007.

[14] J. A. MacBain, J. Conover, and A. Brooker, "Full vehicle simulation for series hybrid vehicles," Nat. Renewable Energy Lab., Golden, CO, USA, Tech. Rep. 2003-01-2301, Jun. 2003.
[15] G. Rizzoni, L. Guzzella, and B. M. Baumann, "Unified modeling of hybrid electric vehicle drivetrains," IEEE/ASME Trans. Mechatron., vol. 4, no. 3, pp. 246-257, Sep. 1999.

[16] L. Guzella and A. Sciarretta, Vehicle Propulsion Systems, 2nd ed. Zurich, Switzerland: Springer-Verlag, Jun. 2007.

[17] D. Opila, X. Wang, R. McGee, R. Gillespie, J. A. Cook, and J. Grizzle, "An energy management controller to optimally trade off fuel economy and drivability for hybrid vehicles," IEEE Trans. Control Syst. Technol., vol. 20, no. 6, pp. 1490-1505, Nov. 2012.

[18] B. Powell and T. Pilutti, "A range extender hybrid electric vehicle dynamic model," in Proc. 33rd IEEE Conf. Decision Control, Dec. 1994, pp. 2736-2741

[19] K. E. Bailey and B. K. Powell, "A hybrid electric vehicle powertrain dynamic model," in Proc. Amer. Control Conf., Jun. 1995, pp. 1677-1682.

[20] K. L. Butler, M. Ehsani, and P. Kamath, "A matlab-based modeling and simulation package for electric and hybrid electric vehicle design," IEEE Trans. Veh. Technol., vol. 48, no. 6, pp. 1770-1778, Nov. 1999.

[21] O. Tremblay, L.-A. Dessaint, and A.-I. Dekkiche, "A generic battery model for the dynamic simulation of hybrid electric vehicles," in Proc. IEEE VPPC, Sep. 2007, pp. 284-289.

[22] K. Chen, A. Bouscayrol, and W. Lhomme, "Energetic macroscopic representation and inversion based control: Application to an electric vehicle with an electrical differential," J. Asian Electr. Veh., vol. 6, no. 1, pp. 1097-1102, Jun. 2008.

[23] Y. Cheng, K. Chen, C. Chan, A. Bouscayrol, and S. Cui, "Global modeling and control strategy simulation," IEEE Veh. Technol. Mag., vol. 4, no. 2, pp. 73-79, Jun. 2009.

[24] K. Chen, A. Bouscayrol, A. Berthon, P. Delarue, D. Hissel, and R. Trigui, "Global modeling of different vehicles," IEEE Veh. Technol. Mag., vol. 4, no. 2, pp. 80-89, Jun. 2009.

[25] D. Chrenko, I. Garcia-Diez, and L. Le-Moyne, "Artificial driving cycles for the evaluation of energetic needs of electric vehicles," in Proc. IEEE Transp. Electr. Conf. Expo, Dearborn, MI, USA, Jun. 2012, pp. $1-5$.

[26] Q. Gong, Y. Li, and Z. Peng, "Trip based optimal power management of plug-in hybrid electric vehicles using gas-kinetic traffic flow model," IEEE Trans. Veh. Technol., vol. 57, no. 6, pp. 3393-3401, Nov. 2008.

[27] D. Ambühl and L. Guzzella, "Predictive reference signal generator for hybrid electric vehicles," IEEE Trans. Veh. Technol., vol. 58, no. 9, pp. 4730-4740, Nov. 2009.

[28] E. Tzirakis, K. Pitsas, F. Zannikos, and S. Stournas, "Vehicle emissions and driving cycles: Comparison of the Athens driving cycle (ADC) with ECE-15 and European driving cycle (EDC)," Global NEST, vol. 8, no. 3, pp. 282-290, May 2006.

[29] M. Koot, J. Kessels, B. de Jager, W. Heemels, P. vanden Bosch, and M. Steinbuch, "Energy management strategies for vehicular electric power systems," IEEE Trans. Veh. Technol., vol. 54, no. 3, pp. 771-782, May 2005 .

[30] A. Konev and L. Lezhnev, "Control strategy optimization for a series hybrid vehicle," Central Autom. Motor Res. Inst. (NAMI), Alvin, TX, USA, Tech. Rep. 2006-01-0663, Apr. 2006.

[31] J. Won and R. Langari, "Intelligent energy management agent for a parallel hybrid vehicle-Part II: Torque distribution, charge sustenance strategies, and performance results," IEEE Trans. Veh. Technol., vol. 54, no. 3, pp. 935-953, May 2005.

[32] C. Quigley and R. McLaughlin, "Using vehicle navigation and journey information for the optimal control of hybrid and electric vehicles," in Proc. Adv. Microsyst. Automotive Appl., 2011, pp. 199-211.

[33] S. Barsali, M. Ceraolo, and A. Possenti, "Techniques to control the electricity generation in a series hybrid electrical vehicle," IEEE Trans. Energy Convers., vol. 17, no. 2, pp. 260-266, Jun. 2002.

[34] M. Hajimiri and F. Salmasi, "A predictive and battery protective control strategy for series HEV," J. Asian Electr. Veh., vol. 6, no. 2, pp. 1159-1165, Dec. 2008.

[35] M. Sorrentino, G. Rizzo, and I. Arsie, "Analysis of a rule-based control strategy for on-board energy management of series hybrid vehicles," Control Eng. Pract., vol. 19, pp. 1433-1441, Aug. 2011.

[36] C. Zhang and A. Vahidi, "Route preview in energy management of plugin hybrid vehicles," IEEE Trans. Control Syst. Technol., vol. 20, no. 2, pp. 546-553, Mar. 2012.

[37] S. Kermani, S. Delprat, T. Guerra, R. Trigui, and B. Jeannere, "Predictive energy management for hybrid vehicle," Control Eng. Pract., vol. 20, no. 4, pp. 408-420, Apr. 2012. 
[38] S. Moura, H. Fathy, D. Callaway, and J. Stein, "A stochastic optimal control approach for power management in plug-in hybrid electric vehicles," IEEE Trans. Control Syst. Technol., vol. 19, no. 3, pp. 545-555, May 2011.

[39] J. Chiasson and L. Tolbert, "A library of SIMULINK blocks for real-time control of HEV traction drives," Oak Ridge Nat. Lab., Univ. Tennessee, Knoxville, TN, USA, Tech. Rep. 02FCC-30, 2002.

[40] M. Amiria, M. Esfahanian, M. Hairi-Yazdi, and V. Esfahanian, "Minimization of power losses in hybrid electric vehicles in view of the prolonging of battery life," J. Power Sour., vol. 190, pp. 372-379, Feb. 2009.

[41] (2013, Mar. 15). Noao, Vehicule Electrique Avec Prolongateur d'autonomie Pole de la Performance Nevers Magny-Cours Magny Cours [Online]. Available: http://www.asso-ppnmc.fr

[42] (2013, Feb. 5). Pistes et Pilotage, la Piste Grand Prix [Online]. Available: http://www.circuitmagnycours.com

[43] D. Chrenko, M.-C. Péra, and D. Hissel, "Inversion-based control of a PEM fuel cell system using energetic macroscopic representation," ASME J. Fuel Cell Sci. Technol., vol. 6, no. 2, p. 024501, May 2009.

[44] M. Ehsani, Y. Gao, S. Gay, and A. Emadi, Modern Electric, Hybrid Electric, and Fuel Cell Vehicles: Fundamentals, Theory, and Design. College Station, TX, USA: CRC Press, 2004.

[45] L. Roberto and E. Simos A., "Lap time optimisation of a sports series hybrid electric vehicle," in Proc. World Congr. Eng., vol. 3. Jul. 2013 , pp. 1-6.

[46] Z. Asus, D. Chrenko, E. H. Aglzim, A. Keromnes, and L. Le-Moyne, "Simple method of estimating consumption of internal combustion engine for hybrid application," in Proc. IEEE Transp. Electr. Conf. Expo, Dearborn, MI, USA, Jun. 2012, pp. 1-6.

[47] S. Wirasingha and A. Emadi, "Classification and review of control strategies for plug-in hybrid electric vehicles," IEEE Trans. Veh. Technol., vol. 60, no. 1, pp. 111-122, Jan. 2011.

[48] A. Sciarretta, M. Back, and L. Guzzella, "Optimal control of parallel hybrid electric vehicles," IEEE Trans. Control Syst. Technol., vol. 12, no. 3, pp. 352-363, May 2004.

[49] F. Salmasi, "Control strategies for hybrid electric vehicles: Evolution, classification, comparison, and future trends," IEEE Trans. Veh. Technol., vol. 56, no. 5, pp. 2393-2404, Sep. 2007.

[50] O. Sundstrom, L. Guzzella, and P. Soltic, "Optimal hybridization in two parallel hybrid electric vehicles using dynamic programming," in Proc. Int. Fed. Autom. Control, Jul. 2008, pp. 4642-4647.

[51] C. Nino-Baron, A. Tariq, G. Zhu, and E. Strangas, "Trajectory optimization for the engine-generator operation of a series hybrid electric vehicle," IEEE Trans. Veh. Technol., vol. 60, no. 6, pp. 2438-2447, Jul. 2011.

[52] Z. Asus, E.-H. Aglzim, D. Chrenko, Z.-H. Che-Daud, and L. Le-Moyne, "Optimization of racing series hybrid electric vehicle using dynamic programming," in Proc. Simul. Energy, Sustain. Develop. Environ., Athens, Greece, Sep. 2013, pp. 1-10.

[53] V. Sezer, M. Gokasan, and S. Bogosyan, "A novel ECMS and combined cost map approach for high-efficiency series hybrid electric vehicles," IEEE Trans. Veh. Technol., vol. 60, no. 8, pp. 3557-3570, Oct. 2011. 